\title{
Increased immunoreactivity of stromal cell-derived factor-1 and angiogenesis in asthma
}

\author{
M. Hoshino*, N. Aoike\#, M. Takahashi\#, Y. Nakamura\#, T. Nakagawa*
}

Increased immunoreactivity of stromal cell-derived factor-1 and angiogenesis in asthma. M. Hoshino, N. Aoike, M. Takahashi, Y. Nakamura, T. Nakagawa. (C) ERS Journals Ltd 2003.

ABSTRACT: Stromal cell-derived factor-1 (SDF-1) acts as a chemoattractant for leukocytes and can induce neovascularisation. To examine the role of SDF-1 in the development of angiogenesis, immunohistochemical studies were performed on bronchial biopsy specimens from asthmatic and control subjects.

Bronchial biopsy specimens were obtained from 13 asthmatic and eight control subjects. The number of vessels and the percentage area they occupied were estimated after staining for type-IV collagen. In addition the number of SDF-1-positive cells was determined.

There was a significant increase in the number of vessels and the percentage vascularity in the submucosa of asthmatic subjects compared with control subjects. Asthmatic subjects exhibited a greater number of SDF-1-positive cells in the airway mucosa than control subjects. The degree of vascularity was associated with the number of SDF-1-positive cells. Furthermore, the number of SDF-1-positive cells was inversely correlated with airway calibre and airway hyperresponsiveness. Colocalisation studies revealed that endothelial cells, macrophages and T-lymphocytes were the major sources of SDF-1.

These findings suggest that increased vascularity of bronchial mucosa in asthmatic subjects is closely related to the expression of stromal cell-derived factor- 1 positive cells, which may play a role in remodelling of airways via angiogenesis.

Eur Respir J 2003; 21: 804-809.
*Dept of Internal Medicine, Division of Respiratory and Infectious Diseases, St. Marianna School of Medicine, Kawasaki, " Second Dept of Internal Medicine, Toho University School of Medicine, Tokyo, Japan.

Correspondence: M. Hoshino

Division of Respiratory and Infectious Diseases Dept of Internal Medicine

St. Marianna University School of Medicine 2-16-1 Sugao, Miyamae-ku

Kawasaki

Japan

Fax: 81449778361

E-mail: mhoshino@marianna-u.ac.jp

Keywords: Airway remodelling airway vascularity

angiogenesis

stromal-cell derived factor-1

Received: September 32002

Accepted after revision: January 22003
It has long been recognised that in fatal asthma, the airway mucosa is oedematous and contains dilated, congested blood vessels [1]. A post-mortem study showed that vascularity (the percentage of lamina propria occupied by vessels), but not the number of vessels, was increased in the small airways mucosa in victims of fatal asthma [2]. In another study of fatal asthmatics there was an increase in both the number of vessels and the vessel area in the cartilaginous airways, suggesting enlargement of existing vessels [3]. It remains unclear whether abnormalities in bronchial vasculature, such as angiogenesis, exist in the airways of asthmatics. Histological examinations of biopsies from mild asthmatics, obtained during bronchoscopy, have shown an increased vessel number and vascularity in the submucosa when compared to control subjects [4]. It has been proposed that angiogenesis contributes to the airway remodelling process in patients with asthma.

Some of the cytokines and growth factors associated with inflammation of the airways appear to play a role in airway remodelling [5] and may be responsible for the increased vascularity observed in the airways of asthmatics. The present authors have recently demonstrated that expression of vascular endothelial growth factor (VEGF), basic fibroblast growth factor (FGF) and angiogenin is related to the increased vascularity observed in the airways of asthmatics [6]. Chemokines and their receptors are known to play an important role in the process of leukocyte trafficking and homing, especially at sites of inflammation, infection and tumour growth. Stromal cellderived factor-1 (SDF-1) is a member of the CXC chemokine family. It is also known as CXCL12 and its specific receptor is known as CXCR4 [7]. In SDF-1 or CXCR4 knockout mice, cardiovascular and neural developments were absent and defective myelopoiesis and lymphopoiesis was observed [8-10]. Therefore, SDF-1 is not considered to be an inflammatory chemokine, but it appears to be involved in certain homeostatic processes. SDF-1 is required for normal cardiovascular development, but the underlying mechanisms resulting in vasculogenesis remain unclear. Furthermore, there are no reports describing any association between SDF-1 and angiogenesis in bronchial asthma. In the present study, the authors hypothesise that SDF-1 may play a critical role in the remodelling of airways. In particular it may be involved in the angiogenesis associated with inflammation of the airways. Thus, SDF-1 expression and vessel production has been investigated, using immunohistochemical techniques, in tissues from asthmatic and control patients.

\section{Subjects and methods}

\section{Subjects}

Thirteen atopic asthmatic patients were diagnosed using the criteria outlined in the National Institute of Health Guidelines [11]. All patients had typical clinical symptoms; a documented $20 \%$ reversibility in peak expiratory flow or forced expiratory volume in one second (FEV1), and airway hyperresponsiveness. Atopy was defined by a wheal reaction $>3 \mathrm{~mm}$ in diameter in response to skin-prick tests using common aeroallergens (e.g. mixed grass, tree pollen, mixed moulds, cat and dog dander and house dust mite). Histamine 
was used as a positive control. Eight nonatopic, normal subjects were recruited from the hospital outpatients department. None of the patients had received inhaled or oral corticosteroid therapy in the 3 months before the study. Patients only inhaled $\beta_{2}$-agonists when bronchodilatation was required. All the subjects were nonsmokers, had no evidence of any other pulmonary disease and had not experienced any upper respiratory tract infections during the 2 weeks preceding the study. The study was approved by the Ethics Committee of the Toho University School of Medicine and all subjects gave written informed consent.

\section{Spirometry and methacholine challenge}

Spirometry was performed and airway methacholine responsiveness was measured using an "Astograph" (TCK-6000CV; Chest MI, Co, Tokyo, Japan), according to the method of TAKISHIMA et al. [12]. Briefly, respiratory resistance (Rrs) was measured using the forced oscillation method $(3 \mathrm{~Hz})$. Methacholine was inhaled continuously and the concentration was increased until $R$ rs reached twice the baseline value. Methacholine chloride was diluted in physiological saline solution with two-fold increasing concentrations from 49 to $25,000 \mu \mathrm{g}$. $\mathrm{mL}^{-1}$. Saline solution was inhaled first, followed after $1 \mathrm{~min}$ by successive inhalations of increased concentrations of methacholine. Bronchial hyperresponsiveness was evaluated as the minimum cumulative dose (Dmin) of methacholine for which the reciprocal of Rrs decreased linearly. Dmin was scaled by a unit equal to $1 \mathrm{~min}$ of a $1.0 \mathrm{mg} \cdot \mathrm{mL}^{-1}$ aerosol inhalation of methacholine. A previous study reported a significant correlation between bronchial hyperresponsiveness as measured by Dmin and the provocative dose causing a $20 \%$ fall in FEV1 (PD20) [13].

\section{Fibreoptic bronchoscopy}

Subjects received an intramuscular injection of atropine and xylocaine was applied to the upper airways. Supplemental oxygen was administered at a rate of $4 \mathrm{~L} \cdot \mathrm{min}^{-1}$ using a nasal catheter and blood oxygen saturation was monitored using a pulse oximeter (Ohmeda, Louisville, KY, USA). A bronchoscope (BF type 1T-30; Olympus Co, Tokyo, Japan) was inserted through the mouth, and biopsy forceps (FB-15C; Olympus) were used to collect 2-3 biopsy specimens from the subcarina separating the left upper and lower lobe bronchi.

\section{Tissue processing}

Biopsy specimens were placed in ornithine carbamyl transferase (OCT) medium (Miles Scientific, Naperville, IL, USA), snap-frozen in liquid-nitrogen cooled isopentane and stored at $-70^{\circ} \mathrm{C}$ until use. For immunochemistry, biopsy tissues were immersed in phosphate-buffered saline (PBS) and cooled on ice. Tissues were then blocked with OCT medium. Cryostat sections $(4 \mu \mathrm{m})$ were cut, air-dried for $1 \mathrm{~h}$ and then fixed by immersion in a mixture of acetone-methanol (60:40) for $7 \mathrm{~min}$. Slides were air-dried and stored at $-70^{\circ} \mathrm{C}$ until use.

\section{Immunochemistry}

Immunohistochemistry was performed using the alkaline phosphate-antialkaline phosphatase (APAAP) method, as previously described [14]. Vessels were identified using an anticollagen type-IV mouse monoclonal antibody (mAb; Monosan, Uden, the Netherlands). Immunostaining for SDF-1 was performed using a SDF-1 mAb (Genzyme-Techne,
Minneapolis, MN, USA). To confirm the phenotype of SDF1-positive cells, double sequential immunohistochemistry was performed as previously described [15]. Briefly, cryostat sections were taken of biopsy specimens and endogenous peroxidase activity was blocked using $1 \% \mathrm{H}_{2} \mathrm{O}_{2}$ and $0.02 \%$ sodium azide in Tris-buffered saline (TBS) for $30 \mathrm{~min}$. A mixture of primary antibodies was then applied. This consisted of the monoclonal anti-SDF-1 antibody and the appropriate $\mathrm{mAb}$ to determine the presence of eosinophils (antimajor basic protein; Harlan Sera-lab. Ltd, Sussex, UK), mast cells (anti-AA1; Dako Ltd, High Wycombe, UK), T-lymphocytes (anti-CD3; Becton Dickinson, Cowley, UK), macrophages (anti-CD68; Dako) or endothelial cells (anti-CD31; Southern Biotechnology, Birmingham, AL, USA). After incubation with the appropriate secondary antibodies, a tertiary layer of streptavidin peroxidase and murine APAAP conjugate was applied. Sections were developed sequentially in Fast Red (APAAP substrate) and diaminobenzidine (peroxide substrate). Appropriate negative controls were included in all immunochemical studies. These included TBS alone, omission of the primary antibodies and the use of an irrelevant mouse immunoglobulin-G antibody. Cell counts were expressed as the percentage of SDF-1 cells that colocalised with major basic protein, AA1, CD3, CD68, or CD31.

\section{Quantification}

To avoid observer bias, all slides were coded before analysis by one observer and read blindly. A computerised colourimetric image analyser (Win ROOF, Mitani Corp, Fukui, Japan) was used to quantify collagen type-IV immunoreactivity in tissues. The entire submucosa, beneath the epithelial basement membrane, was outlined by hand on the colour monitor using an electronic mouse cursor. Vessel numbers were counted in the submucosal area and were then divided by the submucosal area examined to determine the number of vessels per square millimetre of submucosa. All structures internal to the vessel endothelial basement membrane were evaluated as vascular area. The percentage vascularity was determined by dividing the vascular area by the total area of submucosa. The mean size of vessels was estimated by dividing the total vascular area by the total number of vessels for each subject. The number of positively stained cells was counted in the entire submucosal area, excluding mucosal glands and smooth muscle. Results are expressed as the number of positive cells per square millimetre of submucosa.

\section{Data analysis}

Clinical data were expressed as mean (range). A comparison of lung function tests between groups was performed using the unpaired t-test. Cell counts from the tissue sample were expressed as median (range). As the immunohistochemical data were not normally distributed, the KruskalWallis test was used and, if significant, further tested for significance using the Mann-Whitney U-test. The same observer performed at least three replicate measurements and intra-observer reproducibility was assessed using the coefficient of variation for repeat measurements. The intraobserver coefficient of variation ranged from $3-12 \%$ for vessel profiles and was $<5 \%$ for the number of positive cells. Correlation coefficients were obtained using Pearson linear-regression analysis. A $\mathrm{p}<0.05$ was considered to be statistically significant. 
Table 1. - Subject characteristics

\begin{tabular}{lcc}
\hline & Asthmatic subjects & Control subjects \\
\hline Subjects n & 13 & 8 \\
Age yrs & $29(18-39)$ & $31(28-41)$ \\
Sex M:F & $8: 5$ & $5: 3$ \\
FEV1\% pred & $73.2(51.8-89.0)^{* * *}$ & $92.8(85.8-97.1)$ \\
Dmin units & $0.80(0.15-1.69)^{* * *}$ & $>50$ \\
Skin test & positive & negative \\
\hline
\end{tabular}

Values are presented as mean (range). M: male; F: female; FEV1: forced expiratory volume in one second; pred: predicted; Dmin: airway hyperresponsiveness as the minimum cumulative unit is equal to $1 \mathrm{~min}$ of $1.0 \mathrm{mg} \cdot \mathrm{mL}^{-1}$ aerosol inhalation of methacholine. ${ }^{* * *}: \mathrm{p}<0.001$ compared with control subjects.

\section{Results}

\section{Clinical data}

Clinical data from the two study groups are summarised in table 1 . The sex ratio and the age of the subjects were similar between asthmatic and control groups. FEV1, measured as the percentage of the predicted value and Dmin were significantly lower in asthmatic patients than in controls. In addition all asthmatic patients were atopic.

\section{Vascularity}

When comparing asthmatic and control subjects, significant increases were observed both in vessel number $\left(314 \cdot \mathrm{mm}^{-2}\right.$ $(183-375)$ versus $\left.187 \cdot \mathrm{mm}^{-2}(142-240) ; \mathrm{p}<0.001\right)$ and percentage vessel area (10.2\% (5.3-16.4) versus 5.4\% (4.4-6.7); $\mathrm{p}<0.001)$ ) in asthmatic subjects (fig. 1). There was no significant difference in mean vessel size between asthmatics and controls (285 $\mu^{2}(160-582)$ versus $264 \mu^{2}$ (158-360); $\left.\mathrm{p}>0.05\right)$. Examples of anticollagen IV-positive staining of biopsy specimens taken from asthmatic and control subjects are shown in figures $2 \mathrm{a}$ and $\mathrm{b}$.

\section{Immunoreactivity of stromal-cell derived factor-1}

Immunohistochemical staining revealed increased numbers of SDF-1-positive cells in the bronchial mucosa of asthmatic
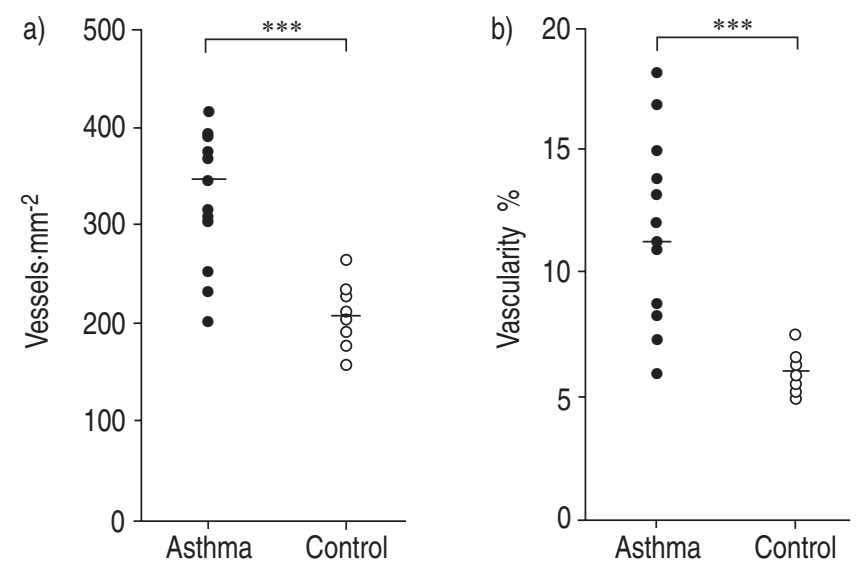

Fig. 1.-a) Number of vessels (square millimetre of submucosa) and b) vascularity (percentage area occupied by vessels) in endobronchial biopsies from asthmatic patients and control subjects. Horizontal bars represent median values. $* * *: \mathrm{p}<0.001$ subjects compared with control subjects $\left(45 \cdot \mathrm{mm}^{-2}(20-86)\right.$ versus $15 \cdot \mathrm{mm}^{-2}(9-25) ; \mathrm{p}<0.001$, fig. 3). Examples of staining for SDF-1 are shown in figures $2 \mathrm{c}$ and $\mathrm{d}$. The number of SDF-1-positive cells was inversely correlated with airway calibre (FEV1 \% predicted; $\mathrm{r}=-0.87, \mathrm{p}<0.001)$ and with Dmin $(\mathrm{r}=-0.63, \mathrm{p}<0.05)$ in subjects with asthma (fig. 4).

\section{Relationship between vascularity and stromal-cell derived factor-1}

A statistically significant correlation was detected between the number of vessels in each subject and positive cellular immunostaining for SDF-1 $(r=0.63, \mathrm{p}<0.05)$. There was also a significant correlation between the percentage vascularity and the number of SDF-1-positive cells $(r=0.76, p<0.01$; fig. 5).

\section{Cellular sources of stromal-cell derived factor-1}

Colocalisation studies were performed to determine the phenotype of cells expressing SDF-1 in the asthmatic airway $(n=10)$. In the submucosa, CD31-positive endothelial cells (mean \pm SD, $35.7 \pm 3.5 \%$ ), CD3-positive T-cells $(27.2 \pm 4.3 \%$ ), and CD68-positive macrophages $(22.4 \pm 3.1 \%)$ were the major cell types expressing SDF-1 (table 2 and fig. 2e and f).

\section{Discussion}

The present study has shown that immunoreactivity of SDF-1 is significantly increased within the airways of asthmatic patients compared with control subjects and also that expression of SDF-1 correlates with submucosal vascularity. Furthermore, the number of SDF-1-positive cells was inversely correlated with airway calibre and hyperresponsiveness. This is the first evidence that SDF-1 may play an important role in angiogenesis in the airways of asthmatic patients.

The increased vascularity found in the asthmatic mucosa suggests that angiogenesis is a component of the chronic inflammatory response in asthmatic patients. This study supports previous findings of both increased vessel numbers and vascularity in asthmatics $[4,16,17]$ and confirms that angiogenesis is a specific characteristic of asthma. Several endothelial-specific immunological markers, such as CD31, CD34 and factor VIII also showed positive staining for mesenchymal components and immune cells. Although the type-IV collagen antibody is not an endothelial-specific marker, it has been shown to be essential for the development of new endothelial cell tubes [18]. Studies using anti-factor VIII have consistently found fewer vessels, or have not detected any significant differences in vascularity in the airways of asthmatics [2, 3]. A recent study by VRUGT et al. [19] evaluated blood vessels with EN-4 and found a marked increase in blood vessel number in patients with severe asthma. Many mediators released during inflammation are potentially capable of causing bronchial vascular dilatation. The use of $\beta_{2}$-agonists in asthma causes vascular dilatation of large airway vessels. Although unlikely to be a major factor, it is possible that $\beta_{2}$-agonists may have contributed to the airway vessel dilatation observed in the airways of asthmatic patients. However, the present results were contrary to those reported by CHU et al. [20]. They found that asthmatic subjects had a similar number of blood vessels and airway vascularity to control subjects. This may be explained by the fact that they included patients with asthma who were being treated with inhaled corticosteroids in their analysis. In previous studies, ORSIDA et al. [16] and the present authors [21] have shown that anti-inflammatory 

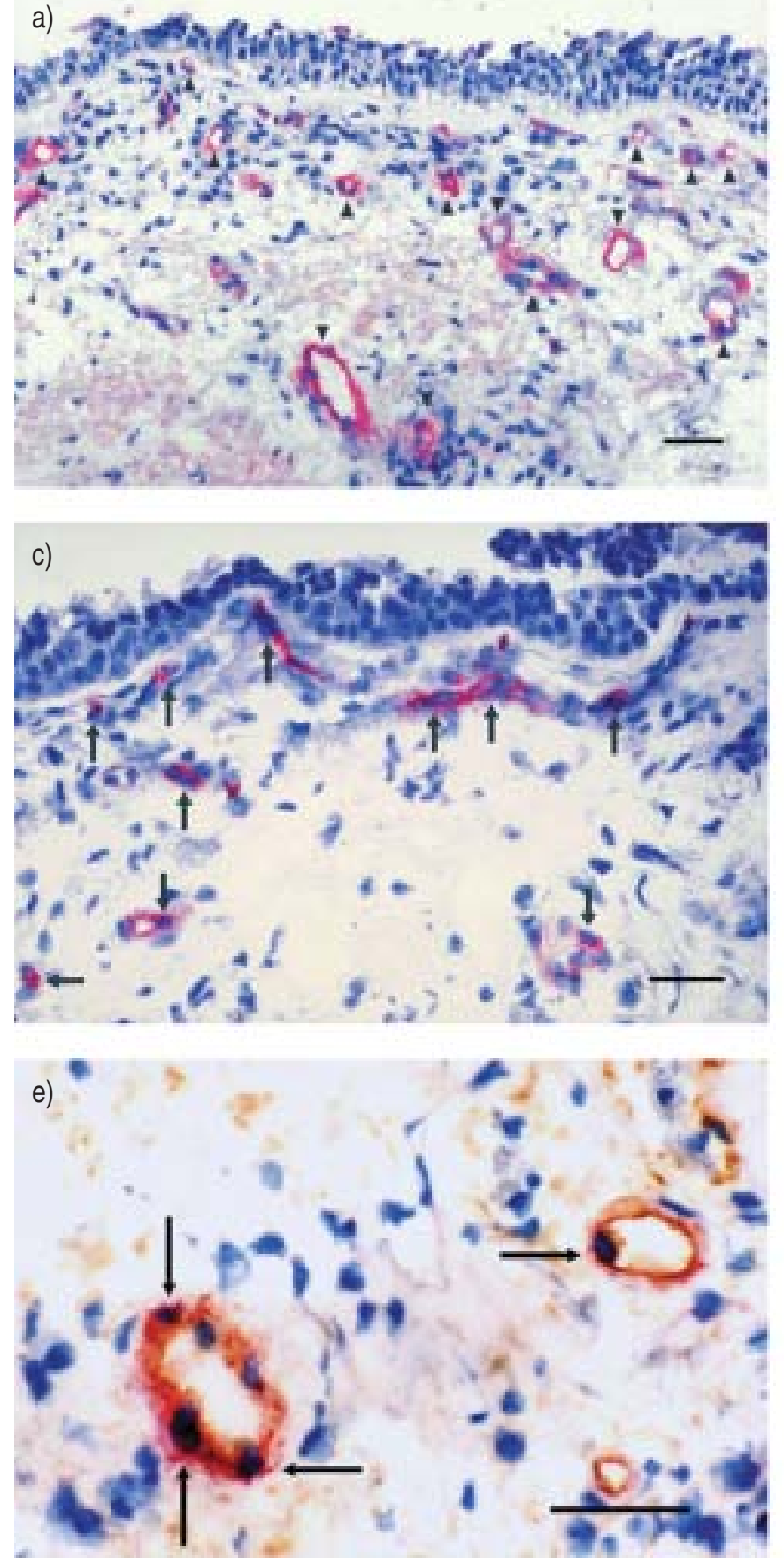
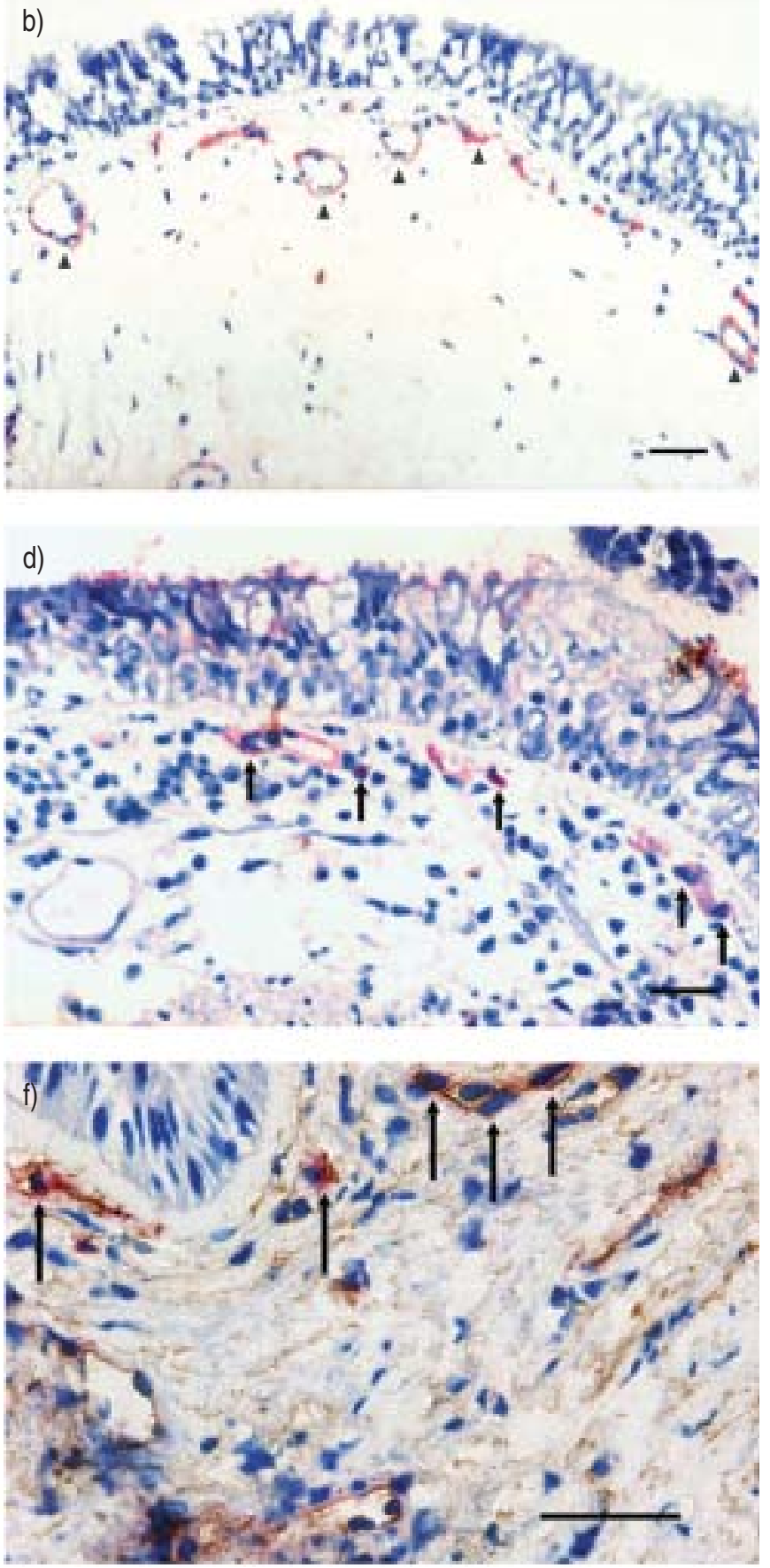

Fig. 2.-Representative photomicrographs of anticollagen type-IV staining in endobronchial biopsies showing vessels in the submucosa of a) a patient with asthma and b) a control subject. Stromal cell-derived factor-1 (SDF-1) detected by immunochemistry in endobronchial biopsy specimens from c) an asthmatic patient and d) a control subject. e) Colocalisation of SDF-1 immunoreactivity (red) and anti-CD31+ endothelial cells (brown); f) CD3 T-cells (brown) in asthmatic bronchial mucosa. Arrowheads indicate vessels. Arrows indicate the cells that react with each antibody. Internal scale bar $=25 \mu \mathrm{m}$.

treatment with corticosteroids reduces the production of growth factors and leads to a reduction in airway vascularity.

Although the role that chemokines play in angiogenesis is currently a focus of intense investigation, little information is available on the mechanisms involved in the pathological remodelling of the asthmatic airway. SDF-1 is a non-aminoterminal Glu-Leu-Arg motif CXC chemokine and it is unique in that it has both angiogenic and angiostatic properties. It has been reported that subcutaneous SDF-1 injections in mice induced formation of local small blood vessels and this was accompanied by infiltration of leukocytes [22]. Conversely, expression of SDF-1 is decreased in dermal wound healing [23]. Mice lacking the SDF-1 gene have defective vascular development, particularly in the gastrointestinal tract, suggesting that SDF-1 plays an important role in organ vascularisation [8]. Recent studies have demonstrated that endothelial cells are strongly chemoattracted to SDF-1 [24-26]. The present authors have shown that there is increased vascularity in asthmatic tissues and further that expression of SDF-1 is upregulated. These findings suggest that SDF-1 is released 


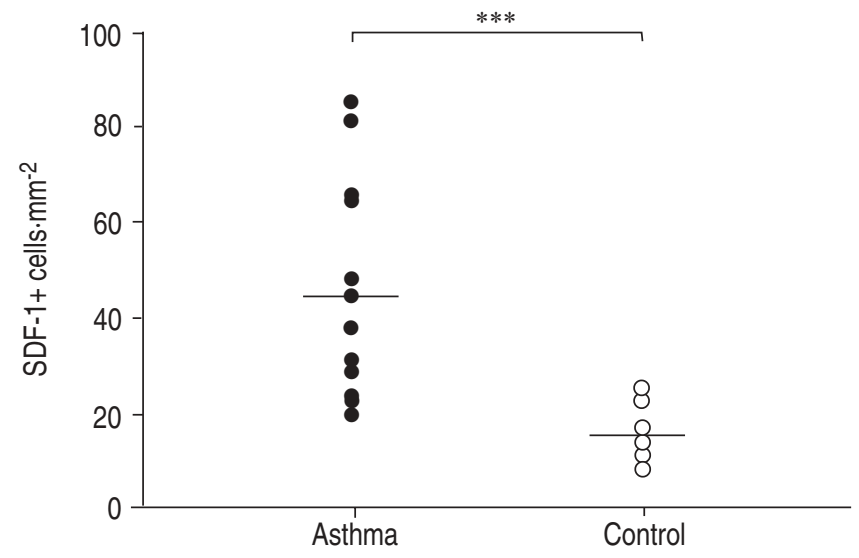

Fig. 3. - Number of stromal cell-derived factor-1 (SDF-1)+ cells in the airway of asthmatic and control subjects. Results are expressed as the number of positive cell per square millimetre of submucosa of airway. Horizontal bars represent median values. ${ }^{* * *}: \mathrm{p}<0.001$.

from asthmatic bronchial tissue and, furthermore, that it is involved in organ vascularisation. It also appears to have chemoattractant properties. Of interest is the finding by SALCEDO et al. [22] that SDF-1 upregulates endothelial VEGF. Recent experiments in the present authors' laboratory [27] have shown that the messenger ribonucleic acid (mRNA) of VEGF and its receptor are over-expressed in the airways of asthmatics. Significant correlations were detected between the
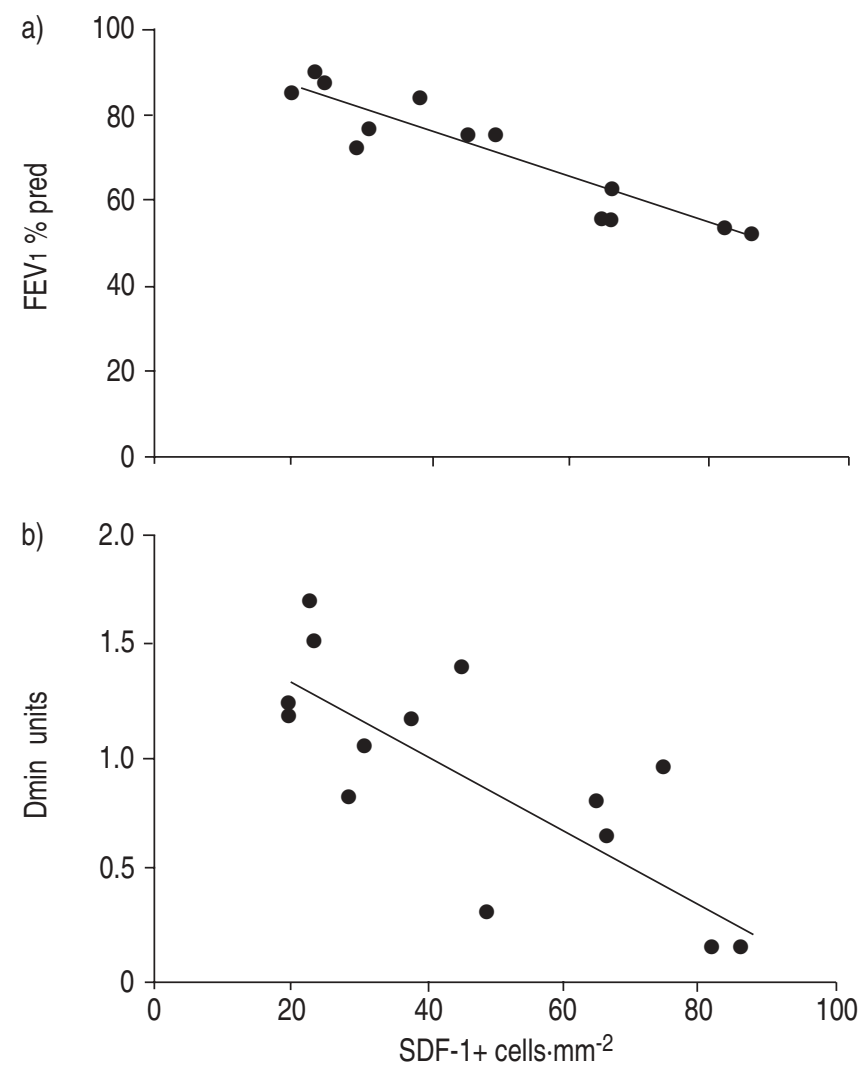

Fig. 4.-Correlation between the number of stromal cell-derived factor-1 $(\mathrm{SDF}-1)+$ cells in bronchial mucosa and a) airway calibre (forced expiratory volume in one second $\left(\mathrm{FEV}_{1}\right) \%$ predicted) $(\mathrm{r}=-0.87, \mathrm{p}<0.001)$ or b) airway hyperresponsiveness evaluated as minimum cumulative dose (Dmin) in asthmatic subjects (the minimum cumulative unit is equal to $1 \mathrm{~min}$ of $1.0 \mathrm{mg} \cdot \mathrm{mL}^{-1}$ aerosol inhalation of methacholine) $(\mathrm{r}=-0.63, \mathrm{p}<0.05)$.

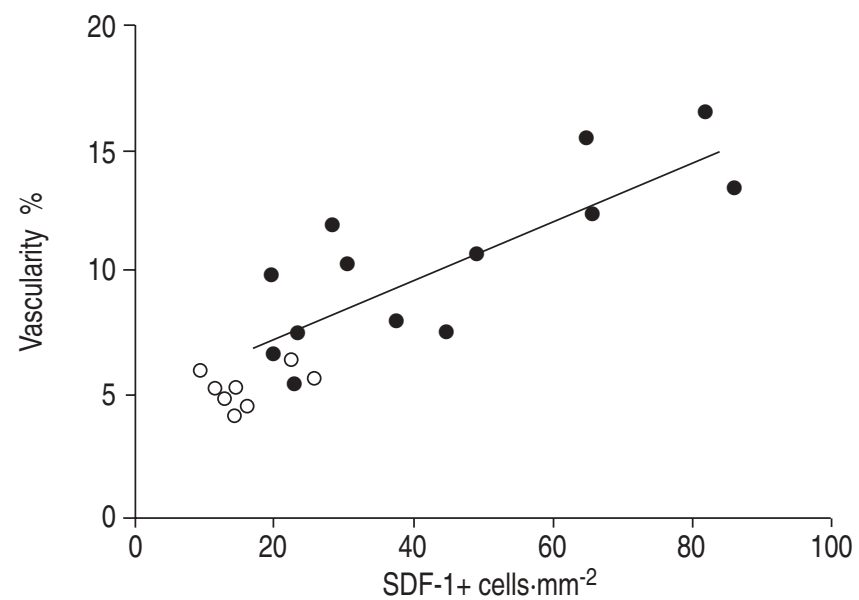

Fig. 5.-Correlation between the percentage of vascularity and stromal cell-derived factor-1 (SDF-1) + cells in bronchial mucosa. data from asthmatic patients; $\bigcirc$ : control subjects. Correlation was significant only in asthmatic patients $(\mathrm{r}=0.76, \mathrm{p}<0.01)$.

Table 2. - Phenotype of stromal cell-derived factor-1 (SDF-1) immunoreactive cells within the submucosa of bronchial biopsy specimens from asthmatic subjects

Percentage of SDF-1 immunoreactive cells

$\begin{array}{lr}\text { MBP+ eosinophils } & 3.2 \pm 2.3 \\ \text { AA1+ mast cells } & 2.6 \pm 1.2 \\ \text { CD3+ T-cells } & 27.2 \pm 4.3 \\ \text { CD68+ macrophages } & 22.4 \pm 3.1 \\ \text { NP57+ neutrophils } & 1.6 \pm 0.9 \\ \text { CD31+ endothelial cells } & 35.7 \pm 3.5\end{array}$

Data are expressed as mean $\pm \mathrm{SD}$; Asthmatic subjects: $\mathrm{n}=10$.

number of SDF-1-positive cells and the number of cells positive for angiogenic factors such as VEGF, basic FGF or angiogenin (data not shown). Therefore, SDF-1 may contribute to angiogenesis during pathological neovascularisation induced by angiogenic factors, such as VEGF, basic FGF or angiogenin, which may render endothelial cells more responsive to SDF-1. The present authors have shown that an increase in the number of SDF-1-positive cells correlates significantly with a reduced airway calibre and responsiveness. Neutralisation of the anti-SDF-1 antibody led to a reduced number of lung eosinophils and reduced airway hyperresponsiveness in a mouse model of allergic airway disease [28]. This finding is consistent with a previous report demonstrating a significant inverse correlation between airway responsiveness and vessel number in the airways of asthmatics [16]. The current findings suggest that the release of SDF-1 from asthmatic airways may contribute to both the development of airway vascularity and to the observed decline in lung function.

Using double sequential immunohistochemistry, the current authors have identified cells expressing SDF-1. Endothelial cells, T-lymphocytes and macrophages within the bronchial mucosa were the most significant cellular sources of SDF-1 in asthmatic subjects. It is well known that SDF-1 is expressed abundantly in cells such as endothelial cells, lymphocytes and monocytes [29]. No direct evidence of CXCR4 expression in vessels inside tissues was found, however, the present authors' findings suggest that SDF-1 may be involved in angiogenesis by causing an increase in vascularity in airway tissues.

In conclusion, the current study shows that expression 
of stromal cell-derived factor-1 is upregulated in bronchial asthma and is associated with the degree of airway vascularity. These results suggest that stromal cell-derived factor-1 plays a role in the angiogenic alterations associated with asthma.

\section{References}

1. Dunnill MS. The pathology of asthma with special reference to changes in the bronchial mucosa. J Clin Pathol 1960; 13: 27-33.

2. Kuwano K, Bosken $\mathrm{CH}$, Pare PD, Bai TR, Wiggs BR, Hogg JC. Small airways dimensions in asthma and in chronic obstructive pulmonary disease. Am Rev Respir Dis 1993; 148: $1220-1225$.

3. Carroll NG, Cooke C, James AL. Bronchial blood vessel dimensions in asthma. Am J Respir Crit Care Med 1997; 155: 689-695.

4. Li X, Wilson JW. Increased vascularity of the bronchial mucosa in mild asthma. Am J Respir Crit Care Med 1997; 156: 229-233.

5. Vignola AM, Kips J, Bousquet J. Tissue remodeling as a feature of persistent asthma. J Allergy Clin Immunol 2000; 105: 1041-1053.

6. Hoshino M, Takahashi M, Aoike N. Expression of vascular endothelial growth factor, basic fibroblast growth factor, and angiogenin immunoreactivity in asthmatic airways and its relationship to angiogenesis. J Allergy Clin Immunol 2001; 107: 295-301.

7. Bleul CC, Farzan M, Choe $\mathrm{H}$, et al. The lymphocyte chemoattractant SDF-1 is a ligand for LESTR/fusin and blocks HIV-1 entry. Nature 1996; 382: 829-833.

8. Tachibana $\mathrm{K}$, Hirota $\mathrm{S}$, Iizasa $\mathrm{H}$, et al. The chemokine receptor CXCR4 is essential for vascularisation of the gastrointestinal tract. Nature 1998; 393: 591-594.

9. Zou Y-R, Kottmann AH, Kuroda M, Taniuchi I, Littman DR. Function of the chemokine receptor CXCR4 in haematopoiesis and in cerebellar development. Nature 1998; 393: 595-599.

10. Nagasawa T, Hirota S, Tachibana K, et al. Defects of B-cell lymphopoiesis and bone- marrow myelopoiesis in mice lacking the CXC chemokine PBSF/SDF-1. Nature 1996; 382: 635-638.

11. National Institute of Health. National Asthma Education and Prevention Program: Guideline for the diagnosis and management of asthma. NIH Publication No. 97-4051. Bethesda, MD, National Institutes of Health, 1997.

12. Takishima T, Hida W, Sasaki H, Suzuki S, Sasaki K. Directwriting recorder of the dose-response curves of the airway to methacholine. Chest 1981; 80: 600-606.

13. Ishii M, Hida W, Suzuki S, Ichinose M, Sasaki H, Takishima T. Comparison of intermittent and continuous inhalation provocation tests. Ann Allergy 1989; 62: 223-228.

14. Bentley AM, Menz G, Robinson DS, Bradley B, Jeffery PK, Durham SR. Identification of T lymphocyte, macrophages, and activated eosinophils in the bronchial mucosa of intrinsic asthma: relationship to symptoms and bronchial hyperresponsiveness. Am Rev Respir Dis 1992; 145: 500-506.

15. Moqbel R, Ying S, Barkans $\mathrm{J}$, et al. Identification of messenger RNA for IL-4 in human eosinophils with granule localization and release of the translated product. J Immunol 1995; 155: 4939-4947

16. Orsida BE, Li X, Hickey B, Thien F, Wilson JW, Walters EH. Vascularity in asthmatic airways: relation to inhaled steroid dose. Thorax 1999; 54: 289-295.

17. Salvato G. Quantitative and morphological analysis of the vascular bed in bronchial biopsy specimens from asthmatic and non-asthmatic subjects. Thorax 2001; 56: 902-906.

18. Rongish BJ, Hinchman G, Doty MK, Baldwin HS, Tomanek RJ. Relationship of the extracellular matrix to coronary neovascularisation during development. $J$ Moll Cell Cardiol 1996; 28: 2203-2215.

19. Vrugt B, Wilson S, Bron A, Holgate ST, Djukanovic R, Aalbers R. Bronchial angiogenesis in severe glucocorticoiddependent asthma. Eur Respir J 2000; 15: 1014-1021.

20. Chu HW, Kraft M, Rex MD, Martin RJ. Evaluation of blood vessels and edema in the airways of asthma patients. Regulation with clarithromycin treatment. Chest 2001; 119: 416-422.

21. Hoshino M, Takahashi M, Takai Y, Sim J, Aoike N. Inhaled corticosteroids decrease vascularity of the bronchial mucosa in patients with asthma. Clin Exp Allergy 2001; 31: 722-730.

22. Salcedo R, Wasserman K, Young HA, et al. Vascular endothelial growth factor and basic fibroblast growth factor induce expression of CXCR4 on human endothelial cells. Am J Pathol 1999; 154: 1125-1135.

23. Fedyk ER, Jones D, Critchley HOD, Phipps RP, Blieden TM, Springer TA. Expression of stromal-derived factor-1 is decreased by IL-1 and TNF and in dermal wound healing. J Immunol 2001; 166: 5749-5755.

24. Gupta SK, Lysko PG, Pillarisetti K, Ohlstein E, Stadel JM. Chemokine receptors in human endothelial cells. Functional expression of CXCR4 and its transcriptional regulation by inflammatory cytokines. J Biol Chem 1998; 273: 4282-4287.

25. Feil C, Augustin HG. Endothelial cells differentially express functional CXC-chemokine receptor-4 (CXCR-4/fusin) under the control of autocrine activity and exogenous cytokines. Biochem Biophys Res Commun 1998; 247: 38-45.

26. Volin MV, Joseph L, Shockley MS, Davies PF. Chemokine receptor CXCR4 expression in endothelium. Biochem Biophys Res Commun 1998; 242: 46-53.

27. Hoshino M, Nakamura Y, Hamid QA. Gene Expression of vascular endothelial growth factor and its receptors and angiogenesis in bronchial asthma. $J$ Allergy Clin Immunol 2001; 107: 1034-1038.

28. Gonzalo J-A, Lloyd CM, Peled A, Delaney T, Coyle AJ, Gutierrez-Ramos J-C. Critical involvement of the chemotactic axis CXCR4/Stromal cell-derived factor- $1 \alpha$ in the inflammatory component of allergic airway disease. J Immunol 2000; 165: 499-508.

29. Pablos JL, Amara A, Bouloc A, et al. Stromal-cell derived factor is expressed by dendritic cells and endothelium in human skin. Am J Pathol 1999; 155: 1577-1586. 